\title{
ALKALOIDS OF Leucojum vernum
}

I. D. Kalshnikov

UDC $547.944 / 945$

It has been established previously by means of preparative TLC that the combined alkaloids of the herbage and bulbs of Leucojum vernum include lycorine, galanthamine, tazettine, and other, unidentified, alkaloids [1].

According to the literature and our investigations, to extract the alkaloids of the Amaryllidaceae from the raw material the most suitable solvents are $2 \%$ sulfuric acid and chloroform, and for purifying the extracts diethyl ether at a $\mathrm{pH}$ of the medium of 2-3. In view of this, we have applied the conditions mentioned above to the isolation of the alkaloids. The comminuted bulbs with roots or the herbage (phase of mass flowering) of the plant $(500 \mathrm{~g})$ were moistened with $300 \mathrm{ml}$ of $10 \%$ ammonia solution and, after steeping for half an hour, were covered with 3.5 liters of chloroform. Six extractions were performed. The solvent was distilled off from the combined extracts in vacuum to a volume of $150 \mathrm{ml}$, and the alkaloids we re extracted with $2 \%$ sulfuric acid. The acid solution was purified by extraction with ether and was made alkaline with concentrated aqueous ammonia. The light brown precipitate so produced was separated off and recrystallized from boiling methanol $[2,3]$. This gave $0.55 \mathrm{~g}$ of a crystalline base with $\mathrm{mp} 254-256^{\circ} \mathrm{C}$. A mixture with lycorine gave no depression of the melting point and the $\mathrm{R}_{f}$ values of both alkaloids in the ether-acetone-diethylamine $(80: 20: 5)$ and chloroform-diethylamine $(9: 1)$ systems were 0.05 and 0.11 , respectively. The hydrochloride had $\mathrm{mp} 213-214^{\circ} \mathrm{C}$. On the basis of these facts the alkaloid isolated was identified as lycorine [2-4].

The alkaloids were re-extracted quantitatively with chloroform from an alkalized solution, and the solvent was distilled off to dryness. The residue, by treatment with boiling acetone, yielded another $0.59 \mathrm{~g}$ of lycorine.

The addition of concentrated hydrobromic acid to a concentrated acetone solution precipitated $0.43 \mathrm{~g}$ of a crystalline hydrobromide with $\mathrm{mp} 268-270^{\circ} \mathrm{C}$ (from ethanol). This hydrobromide has not yet been identified.

From the residue after the evaporation of the acetone and subsequent purification and re-extraction with ether we obtained $0.33 \mathrm{~g}$ of galanthamine hydrobromide with $\mathrm{mp} 247-249^{\circ} \mathrm{C}$, which was identified by means of the melting points of the base and of the hydrobromide and by mixed melting points, and also by chromatographic analysis [2-5].

On the basis of the information obtained, it may be concluded that the spring snowflake is a promising source of lycorine.

After the isolation of the alkaloids mentioned above, another three bases were detected in the mother solutions from the herbage and bulbs by means of TLC.

\section{LITERATURE CITED}

1. K. D. Kalashnikov and M. V. Savicheva, Farmatsiya, 19, No. 1, 26 (1970).

2. A. Gheorghiu and E. Jonescu-Matiu, Ann. Farmac., 20, No. 6, 531 (1962).

3. L. Bubeva-Ivanova, Farmatsiya (Sofia), 2, 23 (1957).

4. H.-G. Boit, Chem. Ber., 87, 5, 681 (1954).

5. A. Abdusamatov, S. A. Khamidkhodzhaev, and S. Yu. Yunusov, Khim. Prirodn. Soedin., 60 (1971).

L'vov State Medical Institute. Translated from Khimiya Prirodnykh Soedinenii, No. 2, p. 259, MarchApril, 1974. Original article submitted June 4, 1973.

(0) 1975 Plenum Publishing Corporation, 227 West 17th Street, New York, N.Y. 10011. No part of this publication may be reproduced, stored in a retrieval system, or transmitted, in any form or by. any means, electronic, mechanical, photocopying, microfilming, recording or otherwise, without written permission of the publisher. A copy of this article is available from the publisher for $\$ 15.00$. 